\title{
Pavlov and the Foundation of Behavior Therapy
}

\author{
Joseph J. Plaud \\ Applied Behavioral Consultants, Inc. and Brown University
}

\begin{abstract}
The foundation, achievements, and proliferation of behavior therapy have largely been fueled by the movement's foundation in behavioral principles and theories. Although behavioral accounts of the genesis and treatment of psychopathology differ in the extent to which they emphasize classical or operant conditioning, the mediation of cognitive factors, and the role of biological variables, Pavlov's discovery of conditioning principles was essential to the founding of behavior therapy in the 1950s, and continues to be central to modern behavior therapy. Pavlov's reliance on a physiological model of the nervous system, sensible in the context of an early science of neurology, has had an implication for behavior therapists interested in the study of personality types. However, Pavlov's major legacy to behavior therapy was his discovery of "experimental neuroses," shown by his students Eroféeva and Shenger-Krestovnikova, to be produced and eliminated through the principles of conditioning and counter-conditioning. This discovery laid the foundation for the first empirically-validated behavior therapy procedure, systematic desensitization, pioneered by Wolpe. The Pavlovian origins of behavior therapy are analyzed in this paper, and the relevance of conditioning principles to modern behavior therapy is demonstrated. It is shown that Pavlovian conditioning represents far more than a systematic basic learning paradigm. It is also an essential theoretical foundation for the theory and practice of behavior therapy.
\end{abstract}

Keywords: behavior therapy, pavlovian conditioning, personality types

La fundación, logros y proliferación de la terapia de conducta han sido ampliamente alimentados por la fundamentación del movimiento en los principios y teorías conductuales. Aunque las explicaciones conductuales de la génesis y el tratamiento de la psicopatología difieren en la importancia que le atribuyen al condicionamiento clásico o al operante, a la mediación de factores cognitivos y al papel de las variables biológicas, el descubrimiento de Pavlov de los principios del condicionamiento fue esencial para la fundación de la terapia de conducta en la década de 1950, y sigue estando en el centro de la moderna terapia de conducta. La confianza de Pavlov en un modelo fisiológico del sistema nervioso, comprensible en el contexto de una temprana neurología, ha tenido implicaciones para los terapeutas de conducta interesados en el estudio de los tipos de personalidad. Sin embargo, el principal legado de Pavlov a la terapia de conducta fue su descubrimiento de las "neurosis experimentales" que, como mostraron sus discípulas Eroféeva y Shenger-Krestovnikova, se producían y eliminaban mediante los principios del condicionamiento y el contracondicionamiento. Este descubrimiento puso la base del primer procedimiento de terapia de conducta empíricamente validado, la desensibilización sistemática, desarrollada por Wolpe. En este artículo se analizan los orígenes pavlovianos de la terapia de conducta y se pone de manifiesto la relevancia de los principios del condicionamiento para la moderna terapia de conducta. Se muestra que el condicionamiento pavloviano representa mucho más que un paradigma sistemático de aprendizaje básico. Es también una fundamentación teórica esencial para la teoría y la práctica de la terapia de conducta.

Palabras clave: terapia de conducta, condicionamiento pavloviano, tipos de conducta

This chapter is dedicated to the enduring legacy and memory of the founder of behavior therapy, Professor Joseph Wolpe, whose earlier collaboration with the author produced portions of the original manuscript.

Correspondence concerning this chapter should be addressed to Joseph J. Plaud, Research Office, 44 Hickory Lane, Whitinsville, MA 01588-1356, USA. Electronic mail may be sent via the Internet to plaud@fdrheritage.org. 


\section{Pavlov and the Foundation of Behavior Therapy}

Behavior therapy is a clinical application of the science of psychology that rests on empirically-validated principles and procedures (Plaud, 2001). Since the first behavior therapy alternatives to the psychoanalysis and related therapies were introduced almost fifty years ago (Wolpe, 1958), continued advancements in behavior therapy have largely been fueled by its foundation on conditioning principles and theories (Eifert \& Plaud, 1998; Wolpe, 1990). In particular, behavior therapy rests solidly on the experimental methodology pioneered by Pavlov. Clinical applications of Pavlovian conditioning principles began as early as 1912, when Eroféeva, one of Pavlov's students, demonstrated the counter-conditioning effect in the laboratory for the first time (Eroféeva, 1912). Behavior therapy has significantly benefited from the methodologically sophisticated procedure for the conditioning of neurotic or anxiety reactions pioneered by Pavlov and his students. However, the mechanistic and speculative neural theory Pavlov employed to explain his results, a function of his physiological training under Tsion and his continued attempts to understand the problems of inhibition and excitation, has had little relevance in accounting for the genesis of persistent unadaptive habits. While Pavlov's focus on neural factors responsible for conditioning phenomena is less relevant to modern behavior therapy, his related emphasis on personality types has also contributed to the adoption of behavior therapy procedures designed to eliminate anxiety responses.

This chapter analyzes the origins of behavior therapy, a clinical extension of the discoveries of Pavlov and his students, and analyzes the relevance of conditioning principles to modern behavior therapy. It is shown that Pavlovian conditioning represents a systematic basic learning paradigm that was essential for the foundation of behavior therapy in the 1950s, and that Pavlov's theorizing about the neural basis of conditioning, adequate in the context of his times but not for modern science, has relevance for behavior therapists concerned with the study of personality types. The central thesis is that Pavlov and his students' discovery of the conditioning paradigm is his most enduring legacy for modern behavior therapy, as well as one of the foundations for the development and proliferation of behaviorally-based therapeutic procedures.

\section{Behavior Therapy Begins with Pavlov}

The discoveries of Pavlov and his students concerning conditioning principles took half a century to be known formally as behavior therapy in the 1950s, however, the foundations of the behavior therapy movement took place in the early part of the twentieth century. In defining the parameters of behavior therapy and formulating the first significant behavioral treatment approach for anxiety, systematic desensitization, Wolpe focused on Pavlov's experimentation in the areas of "experimental neuroses" and counter-conditioning. In 1912 one of Pavlov's students, Eroféeva, published an experiment related to Pavlov's ideas on psychopathology. Eroféeva applied mild electric shock to a dog's skin preceding food delivery, and found that as long as the aversive conditioned stimulus (CS) for food was applied to one part of the dog's body, defensive behaviors were eliminated and replaced by a conditioned salivary response. This effect was termed counter-conditioning, and it was demonstrated that conditioning methods could neutralize the effects of aversive stimulation when paired with an appetitive response. When the shock was later applied to other parts of the dog's body not conditioned in earlier training phases, there was no generalization of the salivary response, and the established conditioned response virtually disappeared, leading the animal to become very excited (Eroféeva, 1912). Given the significance of this finding, that an experimental conditioning procedure could not only produce behaviors described as neurotic through the use of conditioning principles, but also eliminate such behaviors through the systematic application of counterconditioning measures, an experimentally-based paradigm for the study of anxiety responses appeared, laying the groundwork for the development of behavior therapy beginning in the 1950s.

Furthermore, an additional conditioning phenomenon emerged using a very different methodology than that employed by Eroféeva. Unlike Eroféeva's counterconditioning experiment, which applied aversive stimulation directly in the form of mild shock, a study conducted by Shenger-Krestovnikova produced what has come to be known as "experimental neuroses." In this experiment, discrimination training produced excitatory salivary responding to a circular CS, and inhibitory conditioning to an ellipse. The ellipse was then progressively made more circular over successive trials, and when the ratio of the axes of the ellipse reached a value of 9:8, the dog showed great difficulties discriminating between the excitatory and inhibitory stimuli. After 3 weeks had elapsed, the dog was unable to respond correctly to this task or to stimuli that were obvious circles or ellipses. Additionally, it was noted that the dog began to show extreme levels of excitement, howling, and struggling in its apparatus (ShengerKrestovnikova, 1921). Pavlov reasoned that the dog's "neurotic" performance was due to a "collision" between excitatory and inhibitory processes, producing a cerebral pathology (Wolpe, 1996). Important to note in this context is that while Pavlov, the physiologist, concentrated on a neural hypothesis, behavior therapists who followed focused on the experimental procedures employed by Pavlov and his students in the conditioning and counter-conditioning of neurotic responses in the elaboration of the first principles of behavior therapy (Plaud \& Vogeltanz, 1991; Wolpe, 1958, 1989). 
Pavlov (1927) later argued that "it becomes clear on considering all the pathological cases so far described, that the underlying cause of their development is in every instance the same. Broadly, we can regard these disturbances as due to a conflict between the processes of excitation and inhibition which the cortex finds difficult to resolve" (p. 302). This supposed clash between excitation and inhibition was advanced by Pavlov as a viable explanation of the phenomenon which produced "neurotic" behavior. Although not yet named, behavior therapy was finding its definition as a clinical application of Pavlovian conditioning principles, although refinement in Pavlov's methodology would be required. Treatments for "experimental neuroses" derived from Pavlov's neural hypothesis using pharmacological agents, including bromide and caffeine, produced inconsistent or negligible results (Wolpe, 1996). As discussed by Wolpe and Plaud (1997), a central question concerning Pavlov's theoretical legacy to behavior therapy is why one of the most sophisticated experimentalists of modern science adopted a neural (rather than methodological) conceptualization of psychopathology? After all, Pavlov himself (1897) asked, "what is a pathological condition? Is it not the effect produced upon the organism by the encouraging of an unusual condition, or more correctly said, an unusually intensified ordinary condition?" (p. 166, italics added). It was Pavlov's medical training in the great tradition of Russian physiology that most probably accounted for why Pavlov resorted to a physiological, rather than an environmental, interpretation of the "experimental neuroses" data uncovered in his laboratory. For example, Pavlov (1930/1955) writes:

In the course of the past thirty years I, together with my numerous colleagues, have been predominantly engaged in studying the activity of the higher parts of the brain, mainly the cerebral hemispheres; this study has been carried out on the basis of a strictly objective method, the method of the socalled conditioned reflexes. We have collected very considerable material relating not only to the above-mentioned parts of the brain, but to a certain degree also to their pathology and therapy. We are now in a position to produce obvious experimental neuroses in our experimental animals (dogs) and to treat them; and it is not impossible, in our opinion, to produce in the same animals states somewhat analogous to the human psychoses. It was this that induced me to make closer acquaintance with psychiatry, of which almost no traces have remained in my memory since my student days in the medical faculty. (p. 509, italics added)

In sync with the Russian reflexology and physiology of his day, Pavlov sought to account for the behavioral phenomena he and his students were discovering in terms of neural processes.

Pavlov (1931/1955) was interested in basing "psychical activity on physiological facts, i.e., of uniting and identifying the physiological with the psychological, the subjective with the objective, which, I am convinced, is the most important scientific fact of our time" (p. 409). Even though Pavlov believed that the importance of his studies rested on an understanding of the nervous system, the rich experimental data Pavlov elucidated (i.e., the importance of environmentally-based conditioning procedures in producing and eliminating neurotic behavior patterns) stand out as his most significant contribution to the founding of behavior therapy. Pavlov's belief in excitatory and inhibitory processes irradiating from their initiating points in the cortex, and the physiological consequences of this interplay of excitatory and inhibitory neurochemical energies, has no major consequence for the later development of behavior therapy. Liddell (1966) provides interesting insight into this issue:

Consider the situation in Pavlov's and Freud's day. They were medical contemporaries. They were raised in the old mechanistic physiology. Both of them could not get inside the human calvarium or the animal calvarium. The brain in those early days operated in secret within its skull. Now this has all changed. Whereas Pavlov was forced into a speculative neurology based on Sherrington's neurological doctrine of integrative action of the nervous system, Freud, who was a skilled neurophysiologist in his day, rejected this approach and invented psychodynamics. Today, both Pavlov's speculative neurology and Freud's purely speculative psychodynamics are passé: they are old-fashioned. Times have changed. We are in an era of objectivity. A real neurology is replacing the speculative. (p. 146)

\section{The Emergence of a Conditioning-Based Behavior Therapy}

As detailed by Wolpe and Plaud (1997), Wolpe's experimental studies focused on the significance of these early Pavlovian experiments by underscoring the importance of the conditioning procedures central to Pavlov's early studies of "experimental neuroses." For example, in defining the phenomenon, Wolpe (1952) proposed that "an animal is said to have an experimental neuroses if it displays unadaptive responses that are characterized by anxiety, that are persistent, and that have been produced experimentally by behavioral means (as opposed to direct assault on the nervous system by chemical or physical agencies such as poisonings or extirpations)" (p. 16). Wolpe's experiments in neurosis production were originally conducted with twelve domestic cats. The cats were each housed in a cage and presented with an auditory stimulus followed by a small number of high-voltage, low-amperage shocks from an induction coil. The cats showed a variety of negative responses, including clawing, crouching, trembling, howling, spitting, mydriasis, piloerection, and defecation or urination in some cases. Wolpe found that subsequent confinement 
to the cage did not lead to extinction, even over several days in the absence of shock and food-deprived, the cats would not eat meat dropped in front of the cages. Wolpe noted the effects of stimulus generalization, namely that the experimental laboratory and experimenter himself elicited the negative response patterns from the cats. All cats also showed some of these neurotic behaviors outside of the experimental cages.

Wolpe extended his analysis to account for the experimental phenomenon he was studying in his own laboratory. Given the nature and persistence of the neurotic responses Wolpe conditioned in his experimental subjects, it became clear to Wolpe that anxiety responses did not respond to the customary parameters of Pavlovian extinction. Wolpe settled upon feeding as a natural response which would be incompatible with anxiety. The neurotic animals were placed inside the experimental cage after a food deprivation schedule of 48 or 72 hours. When food pellets were dropped in front of them, as before, the cats did not commence eating. A hand-held four inch ebony rod was then introduced into the cages. The experimenter's hand, having previously been established as a conditioned foodapproach stimulus, manipulated the rod and moved the flat end of the rod containing pellets of meat toward the cats' snouts. Wolpe found that in this condition some of the cats began to consume the food. For those animals who resisted eating, Wolpe utilized the principles of stimulus discrimination to feed the cats in situations which were sufficiently different from the original stimulus where the evocation of anxiety responses was not sufficient to inhibit eating. Through counter-conditioning the stimulus each day while the surroundings became progressively closer to the original laboratory setting, and maintaining the eating response, Wolpe found that the cats would eventually eat in the original cages themselves (but the neurotic responses could be evoked once again in the cages by presenting the auditory stimulus that had preceded the shocks in the original trials). Wolpe also employed Masserman's forced solution (Masserman, 1943) in three cats who did not encounter the hand technique. In this procedure, a movable barrier pushed the cats toward the open food box containing the appetizing food. After a time, the cats snatched at the food in hurried gulps, and then engaged in more natural eating responses. In all these procedures that introduced and maintained eating responses in the presence of stimuli that originally elicited anxiety responses, the neurotic reactions were eliminated (Wolpe, 1952).

Using an experimentally rigorous approach, especially in the context of clinical investigations of the time, Wolpe had empirically confirmed that the experimental procedures pioneered by Pavlov and his students had produced neurotic responses, and through the implementation of counterconditioning procedures the conditioning methodology could also undo anxiety responses. The results of these experiments led Wolpe the experimentalist to hypothesize, in line with the essential parameters of Pavlovian conditioning, that if a response incompatible with anxiety can be made to occur in the presence of anxiety-eliciting stimuli, the bond between the anxiety response and its eliciting stimuli will be weakened or eliminated. Wolpe termed this phenomenon the achievement of therapeutic effects by reciprocal inhibition, and the first behavior therapy procedure known as systematic desensitization was born (Wolpe, 1958). The results of Wolpe's experimental methodology and the use of counter-conditioning procedures for curative effects provided significant evidence in line with the experiments produced in Pavlov's laboratory earlier in the century. Wolpe also looked to the learning theory of Hull in order to understand the role of inhibitory processes in the maintenance of anxiety responses. Considering Hull's theorizing on the significance of reactive and conditioned inhibition in the computation of the effective momentary reaction potential, Wolpe reasoned that the process of elimination of learned behaviors involves the weakening of neural connections previously formed in learning trials. This process, Wolpe hypothesized, could be achieved by simple extinction or reciprocal inhibition, and in both instances drive reduction plays as important a role as in the acquisition of learned behavior. In the case of anxiety, where extinction does not provide a drive reduction mechanism, reciprocal inhibition allows for drive reduction of the excitation that would have led to the given response, and if the response that was dominant is rewarded, its own drive becomes reduced as well (Wolpe, 1952). The environmental situation had also led to a secondary or learned drive state, which caused the organism to engage in avoidance responses, negatively reinforcing the emission of anxiety responses. In his consideration of Hullian behavior theory, then, Wolpe had interlaced several of the major features of the Pavlovian methodology of conditioning with the operant behavioral aspects of the robustness and longevity of anxiety responses.

This combined approach to understanding the acquisition and subsequent maintenance of fear and avoidance behavior is tied to the anxiety-reduction theory of Mowrer's (1939) and Dollard and Miller's (1950) two-process (or two-factor) theory. According to this experimental model, for example, a picture of a spider elicits fear and leads to acquisition and maintenance of an avoidance response, through the mechanisms of negative reinforcement; i.e., an avoidance ritual reduces the intensity of the aversive stimulus and by definition will itself be strengthened as a response set (Levis, 1989). Avoidance behavior develops to reduce fear. According to two-process theory, because of extensive generalization caused by the severity or duration of the CS for fear, avoidance responses so common in the clinical presentation of phobia may remain robust and stable, such that the feared stimulus is almost completely avoided for a great amount of time.

The reliance Wolpe gave to a Pavlovian-based conditioning approach integrating Hullian behavior principles 
led to the first major non-psychoanalytic and empiricallyvalidated behavior therapy, systematic desensitization (Wolpe, 1958; Wolpe \& Plaud, 1997). As the procedure has evolved, the anxious patient is first trained in progressive muscle relaxation exercises, and then gradually exposed via imagery or in vivo to feared stimuli while simultaneously relaxing (i.e., using the learned techniques of muscle relaxation-the mechanism of reciprocal inhibition or counter conditioning). The patient constructs a fear hierarchy, and commencing with the least feared item, gradually progresses up the hierarchy to the most feared item. In line with the theoretical rationale presented above, the anxious patient can not be simultaneously fearful and relaxed, therefore stimuli that are incompatible with the fear response will reciprocally inhibit anxiety responses, leading to their diminishment. Multiple studies over the past 35 years have supported its clinical efficacy as a main treatment for a variety of neurotic responses, including specific and social phobias (Plaud \& Vavrovsky, 1998).

\section{Pavlov and Personality Types: The Other Legacy for Behavior Therapy}

Wolpe's work provided for a clinical extension of the basic procedures pioneered by Pavlov and his students. Most notably, Pavlov's discoveries of the principles of conditioning, especially in collaboration with his students Eroféeva and Shenger-Krestovnikova, laid the essential foundation for the emergence of behavior therapy in the 1950s, which was reflected in the first empirically-validated behavior therapy procedure, systematic desensitization. As the twentieth century gave way to the twenty first, it is clear that the principles of Pavlovian conditioning as well as operant conditioning continue to provide the necessary foundation for ongoing advancement of behavior therapy.

Pavlov's emphasis on a neural basis for conditioning has had impact on some behavior therapists interested in the study of personality types. One of the founders of behavior therapy, Eysenck, is representative of this tradition in behavior therapy. Pavlov (1927) drew significant attention to the study of factors relating to the anxious personality. Pavlov noted that the dogs in his and his students' experiments manifested very different personalities in terms of friendliness, aggressiveness and timidity (Hollandsworth, 1990). It did not take Pavlov long to theorize that these personality differences might have a human counterpart, which led him to formulate a theory of nervous types (Pavlov, 1927). According to Pavlov, individual nervous systems vary in their levels of excitation or inhibition. Additionally, he proposed that combinations of these two factors, which vary along physiological dimensions, determine various personality types. Pavlov argued that the strength of a particular nervous system is a function of balance or homeostasis of inhibitory and excitatory forces.
He proposed that individuals whom he described as nervous types or weak systems would over-respond to mild stimuli and become exhausted quickly. Additionally, he proposed that the weak nervous system would respond with a reduction in strength when the individual was exposed to very high levels of stimulation. Pavlov hypothesized that a reduction in strength would further weaken the ability of the nervous system to defend against additional stimulation. He hypothesized that strong types (i.e., individuals with well-balanced nervous systems) would respond to powerful stimuli for prolonged time periods with no adverse results (Hollandsworth, 1990).

Eysenck (1967) was the clinical scientist to take the next logical step in this domain by developing a comprehensive theory of the biological basis of personality. Eysenck incorporated Pavlov's hypothesis concerning the excitatory and inhibitory forces of the nervous system, and hypothesized that individual differences in resting levels of cortical arousal are genetically influenced. He also hypothesized that cortical arousal was associated with different emotions: Moderate levels of arousal were associated with pleasant emotions, while extreme high or low arousal levels were associated with unpleasant or negative emotions. Based upon the equilibrium theory developed by Pavlov, Eysenck proposed that individuals attempt to bring their cortical arousal either up or down in order to achieve a moderate or homeostatic level of arousal. However, because predetermined, genetic individual differences exist in baseline levels of cortical arousal, stable behavioral differences may emerge throughout the life of the individual. Physiological mechanisms implicated in Eysenck's theory appear to be found in the ascending reticular activating system (Eysenck, 1967).

Hypothesized differences in these levels of cortical arousal led Eysenck to differentiate between individuals who were extroverts (very low levels) and individuals who were introverts (very high levels). While extroverts strive to modulate their levels of arousal by seeking out stimulation, introverts attempt to moderate arousal by avoiding stimulation. Extroversion and introversion comprise one axis of Eysenck's theory of personality. The other axis of personality in Eysenck's theory is composed of the factors of neuroticism and stability. Eysenck proposed that the reactivity level of the autonomic nervous system feeding back to the limbic system is also a genetically determined trait. Individuals with high autonomic reactivity would be classified as neurotic and to have great difficulty in adjusting to novel stimulation. This combination of high baseline autonomic nervous system reactivity with high baseline levels of cortical arousal formed the basis of Eysenck's definition of the anxious personality type (i.e., the neurotic introvert).

With regard to behavior therapy, for better or worse, Pavlov's theory of personality types, especially reflected in the theoretical and scientific extensions of Eysenck, have 
led to a threshold model of neuroticism and therapy approaches to alleviating suffering. According to this model derived from Pavlovian personality types, genetic factors predispose individuals to react in certain ways to particular environmental stimuli. Far from downplaying the role of the environment, Eysenck (1987a) argues that differences in the acquisition and maintenance of neurotic behavior is an interplay between biological predisposition and environmental factors: "There are no fears that are completely inherited; genetic influences can only prepare the organism for the speedy conditioning or learning of specific fear stimuli and fear responses" (p. 396). Therefore, according to this theory based on Pavlovian personality variability, it also becomes important for behavior therapists to consider personality factors in devising specific therapeutic strategies: "It seems likely that if behavior therapists were to pay more attention to personality and individual differences in the treatment of neurotic disorders, they might be more successful than they are at present" (Eysenck, 1987a, p. 398).

Further, Eysenck questioned some of the traditional Pavlovian conditioning interpretations of one of the more popular studies cited in the behavioral literature to account for the conditioning of neurotic responses: Watson and Rayner's (1920) famous Little Albert B. experiment. In this experiment, Watson and Rayner paired a loud noise with a white rat that a child (Albert B.) previously had been playing with quite happily. After repeated presentations of the white rat with the unconditioned stimulus (UCS) for fear, the white rat became a CS for fear, and Albert B. became very upset at the sight of the white rat. Therefore, the basic Pavlovian paradigm was extended to the conditioning of emotive or neurotic responses. As such, utilizing the basic respondent conditioning paradigm, an indifferent (or neutral) stimulus becomes associated with fear by its being paired with an unconditioned stimulus for fear (such as a loud noise or an actual spider or snake). The neutral stimulus, after associative (or contingent) pairings, comes itself to elicit a fear response (conditioned response, CR) according to the principles of Pavlovian conditioning. After Watson and Rayner's early study, later experiments conducted by one of Watson's protégés, Jones (1924), showed that conditioning was essential to the production and elimination of neurosis.

Eysenck (1987b) has been critical of conceptualizing the conditioning of emotional responses such as fear in terms of Pavlovian type A conditioning (i.e., the basic respondent conditioning paradigm in which an indifferent stimulus becomes associated with a CR by its being contingently paired with a UCS). Rather, according to Eysenck, the conditioning of neurosis is best understood through the mechanisms of Pavlovian type B conditioning, in which the CS is closely related or part of the UCS that elicits a complete unconditioned response (UCR), and may also intensify the original CS. For example, Campbell, Sanderson, and Laverty (1964, discussed in detail by Forsyth \& Eifert,
1998) conditioned an intense fear response in human subjects to neutral tones in a single trial by using succinylcholine as the UCS, a preparation which produces immediate respiratory paralysis. Once injected, subjects could not breathe, and could not control other interoceptive effects produced by the drug resulting uniformly in subjects believing they were suffocating and dying. The principal factor that seems to account for rapid acquisition of conditioned fear responses in these patients is the strength and similarity between the nausea induced properties of the drug (UCS) and the intensity of the initial nausea response (UCR). Again, we see that it is the conditioning procedure itself and its unique stimulus and response properties that leads to the acquisition of fear responses.

In other studies, experimenters have found that many objects or situations did not easily serve as CSs for fear, as did Watson's white rat. Seligman (1971) has proposed that humans are prewired or biologically prepared to fear certain stimuli (such as snakes, rats, etc.). Accordingly, some stimuli (such as ducklings, flowers) are extremely difficult to become conditioned stimuli for fear. Several researchers have questioned the validity of this hypothesis in favor of a modified view (refer to Öhman, Ericksson \& Olofsson, 1975, for a thorough review). Wolpe (1990) points out that what is most probably responsible for this preparedness effect is the fact that in the normal course of life objects such as flowers and houses become strongly associated with pleasant or neutral responses; therefore, such experiences actually inoculate humans against developing anxiety responses to such stimuli.

\section{Pavlov's Enduring Legacy to Behavior Therapy}

Conditioning experiments conducted by Pavlov and his students in the early part of the last century continue to provide for a comprehensive database essential to modern scientific psychology in the present century, and the work of Pavlov has contributed enormously to the founding and advancement of behavior therapy. Although two of the founders of behavior therapy, Eysenck and Wolpe, emphasize different elements of the Pavlovian paradigm, it is clear that the conceptualization and the treatment of psychopathology, especially in the area of anxiety responses, owes much to the systematic research in the Pavlovian conditioning tradition.

Pavlov's model of neural functioning, sensible in the context of the early science of neurology, has had little relevance for the foundation or advancement of behavior therapy. As Wolpe (1996) summarizes, "there is a chilling irony in Pavlov not realizing that experimental neuroses were a phenomenon within his very own territory-a function of conditioning"(p. 104). Nevertheless, Pavlov's related hypotheses concerning the importance of personality types has contributed to research on the interaction between 
biological and environmental factors in producing and eliminating conditioned responses. Further, Pavlov pioneered a set of experimental procedures, collectively known as conditioning, that allowed those who followed to apply the richness of the methodology to understanding the genesis of certain neurotic behavior patterns, and to design robust, empirically-validated behavior therapy regimens, such as systematic desensitization.

The applied legacy of Pavlov can be summarized by reviewing, as Eysenck (1988) has detailed, some of the major differences between Freudian psychotherapy and behavior therapy. In line with the rigor of Pavlov's experimental method, behavior therapy, according to Eysenck, is based on a consistent theory leading to testable deductions (some of which have been discussed in this paper); it is derived from experimental studies (such as Wolpe's experiments on conditioning and counter-conditioning); behavior therapists consider symptoms as unadaptive conditioned responses (similar to Wolpe's definition of "experimental neuroses"); behavior therapists believe that symptomatology is determined in part by accidental environmental circumstances (as seen in the basic procedures employed by Pavlov and his students); all treatment of neurotic disorders is concerned with habits existing at present (as exemplified by our discussion of systematic desensitization); "cures" in behavior therapy are achieved by treating the symptom itself, that is, by extinguishing unadaptive CRs and establishing desirable CRs (again, exemplified by systematic desensitization); symptomatic treatment leads to permanent recovery provided autonomic as well as skeletal CRs are extinguished (as seen in Wolpe's focus on reciprocal inhibition and learning); and personal relations are not essential for cures, although they may be useful (especially as a source of social reinforcement).

The debt that modern behavior therapy owes to the prolific and heuristic research paradigm generated by Pavlov, and extended by his students such as Eroféeva and ShengerKrestovnikova, is both significant and enduring. Not only did Pavlov provide much of the intellectual impetus for the founding of the behavior therapy movement, but the conditioning-based procedures he pioneered continue to provide a stimulus for theoretical and procedural refinements for modern behavior therapy. As Eifert and Plaud (1998) conclude in their analysis of the relevance of behavior theory for behavior therapy, while the behavior therapy movement has been a notable achievement in the history of psychological science, and the behaviorisms (such as Pavlovian behaviorism) have made important contributions to the growing success of behavior therapy, the field will ultimately be more successful if it continues to draw upon the resources created by recent advances in basic behavioral theory and research. It is clear that the Pavlovian paradigm offers the resources required to build conceptual, methodological, and practical bridges that help behavior therapists recognize the utility and potential of these new developments. To make advances in behavior theory relevant for behavior therapy, new theoretical concepts and findings need to be related to existing knowledge and clinical practice. Behavior therapists will undoubtedly continue to draw upon the methodologies pioneered by Pavlov, which will be required scholarship for the further development and advancement of behavior therapy. The work of Pavlov, therefore, far from being a thing of the past, will continue to be one of the major legacies for the future of behavior therapy. As we enter a new century devoted to psychological science (Plaud, 2001), it is time to reexamine the nature of our discipline as a behavioral science, a science whose foundation rests largely on the experimental achievements due to the legacy of Pavlov.

\section{References}

Campbell, D., Sanderson, R., \& Laverty, S. G. (1964). Characteristics of conditioned response in human subjects during extinction trials following a single traumatic conditioning trial. Journal of Abnormal and Social Psychology, 66, 627-639.

Dollard, J., \& Miller, N. E. (1950). Personality and psychotherapy. New York: McGraw-Hill.

Eifert, G. H., \& Plaud, J. J. (1998). From behavior theory to behavior therapy: An overview. In J. J. Plaud \& G. H. Eifert (Eds.), From behavior theory to behavior therapy (pp. 1-14). Boston, MA: Allyn \& Bacon.

Eroféeva, M. N. (1912). Electrical stimulation of the skin of the dog as a conditioned salivary stimulus. Unpublished doctoral dissertation, Petrograd.

Eysenck, H. J. (Ed.). (1967). The biological basis of personality. Springfield, IL: Charles C. Thomas.

Eysenck, H. J. (1987a). The role of heredity, environment, and "preparedness" in the genesis of neurosis. In H. J. Eysenck \& I. Martin (Eds.), Theoretical foundations of behavior therapy (pp. 379-402). New York: Plenum Press.

Eysenck, H. J. (1987b). Behavior therapy. In H. J. Eysenck \& I. Martin (Eds.), Theoretical foundations of behavior therapy (pp. 3-35). New York: Plenum Press.

Eysenck, H. J. (1988). Psychotherapy to behavior therapy: A paradigm shift. In D. B. Fishman, F. Rotgers, \& C. M. Franks (Eds.), Paradigms in behavior therapy: Present and promise (pp. 45-76). New York: Springer.

Forsyth, J. P., \& Eifert, G. H. (1998). Phobic anxiety and panic: An integrative behavioral account of their origin and treatment. In J. J. Plaud \& G. H. Eifert (Eds.), From behavior theory to behavior therapy. Boston, MA: Allyn \& Bacon.

Hollandsworth, J.G. (Ed.). (1990). The physiology of psychological disorders. New York: Plenum Press.

Jones, M. C. (1924). A laboratory study of fear: The case of Peter. Pedagogical Seminary, 31, 308-315.

Levis, D. J. (1989). The case for a return to a two-factor theory of avoidance: The failure of non-fear interpretations. In S. B. Klein \& R. R. Mowrer (Eds.), Contemporary learning theories: Pavlovian conditioning and the status of traditional learning theory (pp. 227-277). Hillsdale, NJ: Erlbaum. 
Liddell, H. S. (1966). The challenge of Pavlovian conditioning and experimental neuroses in animals. In J. Wolpe, A. Salter, \& L. J., Reyna (Eds.), The conditioning therapies: The challenge in psychotherapy (pp. 127-148). New York: Holt, Rinehart and Winston.

Masserman, J. H. (1943). Behavior and neurosis. Chicago, IL: University of Chicago Press.

Mowrer, O. (1939). A stimulus-response analysis of anxiety and its role as a reinforcing agent. Psychological Review, 46, 553565.

Öhman, A., Ericksson, A., \& Olofsson, C. (1975). One-trial learning and superior resistance to extinction of autonomic responses conditioned to potentially phobic stimuli. Journal of Comparative and Physiological Psychology, 88, 619-627.

Pavlov, I. P. (1897). Lectures on the work of the principal digestive glands. St. Petersburg.

Pavlov, I. P. (1927). Conditioned reflexes. London: Oxford University Press.

Pavlov, I. P. (1930/1955). Selected works. Moscow: Foreign Languages Publishing House.

Pavlov, I. P. (1932/1955). Selected works. Moscow: Foreign Languages Publishing House.

Plaud, J. J., \& Vavrovsky, K. G. (1998). Specific and social phobias. In J. Wodarski \& B. Thyer (Eds.), Handbook of empirical social work practice (pp. 327-341). New York: Wiley.

Plaud, J. J., \& Vogeltanz, N. D. (1991). Behavior therapy: Lost ties to animal research? The Behavior Therapist, 14, 89-93, 115.

Plaud, J. J. (2001). Clinical science and human behavior. Journal of Clinical Psychology, 57, 1089-1102.
Seligman, M.E.P. (1971). Phobias and preparedness. Behavior Therapy, 2, 307-320.

Shenger-Krestovnikova, N. R. (1921). Contributions to the physiology of differentiation of visual stimuli, and determination of limit of differentiation by the visual analyzer of the dog. Bulletin of Institute of Lesgaft, iii.

Watson, J. B., \& Rayner, R. (1920). Conditioned emotional reactions. Journal of Experimental Psychology, 3, 1-14.

Wolpe, J. (1952). Experimental neuroses as learned behavior. British Journal of Psychology, 43, 243-268.

Wolpe, J. (1954). Reciprocal inhibition as the main basis of psychotherapeutic effects. Archives of Neurology and Psychiatry, 72, 205-226.

Wolpe, J. (1958). Psychotherapy by reciprocal inhibition. Stanford: Stanford University Press.

Wolpe, J. (1989). The derailment of behavior therapy: A tale of conceptual misdirection. Journal of Behavior Therapy and Experimental Psychiatry, 20, 3-15.

Wolpe, J. (1990). The practice of behavior therapy ( $4^{\text {th }}$ ed.). New York: Pergamon Press.

Wolpe, J. (1996). When Pavlov forsook conditioning. Contemporary Psychology, 41, 103-105.

Wolpe, J., \& Plaud, J. J. (1997). Pavlov's contributions to behavior therapy: The obvious and the not so obvious. American Psychologist, 52, 966-972.

Received July 28, 2003

Revision Received September 29, 2003

Accepted October 3, 2003 